\title{
Companies' perception toward manufacturing execution systems
}

\author{
Adil Aramja ${ }^{1}$, Oualid Kamach ${ }^{2}$, Rachid Elmeziane ${ }^{3}$ \\ ${ }^{1,2}$ Laboratory of Innovative Technologies, Abdelmalek Essaadi University, Morocco \\ ${ }^{3}$ Senior Data Scientist Consultant, Devoteam Belgium, Belgium
}

\begin{tabular}{l} 
Article Info \\
Article history: \\
Received Aug 17, 2020 \\
Revised Nov 2, 2020 \\
Accepted Dec 5, 2020 \\
\hline Keywords: \\
Horizontal integration \\
Industry 4.0 \\
MES \\
MES modules \\
PLS-SEM
\end{tabular}

\begin{abstract}
The use of information systems in manufacturing sector is very crucial to reach a high level of operational excellence and improve companies' competitiveness. The use of such systems will definitely increase in the upcoming years, considering the digitalization strategies. Manufacturing execution systems gained a lot of attention in recent years due to showcased benefits in production management operations. Companies that adopted such systems witnessed an increase in process efficiency and enhancements with regards to cost savings and products quality. This paper seeks to analyze what makes the usage of manufacturing execution systems successful among manufacturing companies. We analyzed how the integration capabilities of such systems with other business applications and the company profile impact their usage and consequently the perceived benefits. A case study was conducted with 51 manufacturing companies and data were analyzed using partial least square structural equation modeling technique. The results confirmed the positive and significant impact of the company profile and solution integration capabilities on system usage. In addition, a ranking of solution modules importance for companies was also provided.
\end{abstract}

This is an open access article under the CC BY-SA license.

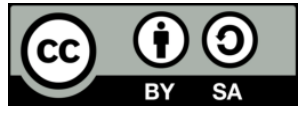

\section{Corresponding Author:}

Adil Aramja

Laboratory of Innovative Technologies (LIT)

Abdelmalek Essaadi University

Tétouan, Morocco

Email: adil.aramja@uae.ac.ma

\section{INTRODUCTION}

Manufacturing execution systems (MES) are considered one of the key components of the smart manufacturing strategy [1]. These information systems (IS) are meant to orchestrate the different production tasks. Their primary role is to monitor the execution of every production process and control of operations at the shop floor level [2]. They also play a central role by ensuring information transition between the shop floor level and business level [3]. In addition, MES allow an easy and timely decision making with regards to the allocation and management of the company's resources. According to [4], MES can help for example with:

- The identification of all current work orders in order to assess the effect of an immediate engineering change order

- The optimization of Work-order sequence and the identification of the most important factors

- The re-scheduling of current work orders to allow preventive maintenance tasks for a specific process

- The automatic retrieval of inventory to be sent to a specific machine at the right time to match the production schedule 
The manufacturing enterprise solutions association (MESA), a non-profit organization that groups manufacturing ecosystem stakeholders for the purpose of sharing best management practices regarding the application of information technology, conducted a study with MES users and came up with the following list of benefits [5]:

- Reduction of manufacturing cycle times

- Reduction of data entry time and paperwork between shifts

- Responds to unanticipated events

- Improvement at both product quality and customer service requests

Many papers demonstrated the value and benefits of MES through case studies with specific companies. Mahmoud et al. [6] described the value brought by MES to a plastic manufacturing company. Actually, the company managed to eliminate paper work, ensure a timely reporting about equipment status and breakdowns to maintenance departments and real time monitoring of production processes. In [7], the authors investigated the importance of implementing MES on the basis of defined strategic competitive priorities which were: Cost, quality, delivery, flexibility, reliability, product conformity and manufacturing and strategic business integration. A case study was conducted with a multinational rolling aluminum company and showed several improvements regarding the reduction of the setup time, improving information quality, increasing product traceability and reduction of products non-conformity and also the identification of organizational factors that would participate in the success of MES implementation.

With all the advantages and benefits that MES may present, yet the consideration of such solution is not an easy and straightforward decision. Actually, while companies with several production sites across different countries would justify easily an investment in MES solution to monitor production across all the sites and ensure economies of scale, small and medium industries would undergo a thorough process to take such decision, especially the ones in emerging economies. As a matter of fact, Franzosa (2017) showed that MES was up till today highly adopted in North America and Western Europe markets, which nowadays are considered as replacement markets for MES solutions. Interestingly, in 2020 the growth rates for MES projects will come essentially from emerging economies [8].

Our efforts in this paper will focus on assessing the perception manufacturing companies have about the importance of MES information systems. Since existing works relied more on a case studies with a specific company, we adopt a new approach by analyzing and confirming the relationship the company profile and MES integration capabilities have with MES perceived usefulness. Our analysis will rely on a quantitative study with several manufacturing companies using MES already. The answers will be analyzed statistically using PLS-SEM.

To the best of our knowledge, this is the first study to analyze statistically the MES importance in Morocco. We were assisted by MES solutions integrators (MSIs) whom agreed to bring their expertise on MES acquisition projects and help us collect data from their manufacturing customers respectively. MSIs are a key player in the MES value chain since they stand between the customer and the MES solution provider, which are located generally overseas.

\section{THEORITICAL FRAMEWORK}

The theoretical framework of our model was developed based on a semi structured interviews conducted with the three identified MSIs. We asked about the most important aspects for manufacturing companies when considering MES. According to interviewed experts, the following elements are the most important ones:

- The offered MES modules and features that is the perceived usefulness (PU).

- The integration capabilities (IC) of MES with other business applications, such as with enterprise resource planning (ERP) or material resource planning (MRP) solutions.

- The company profile (COMPRO) that is what the company operating industry and what type of manufacturing process in which it is implicated.

\subsection{MES perceived usefulness}

The perceived usefulness (PU) of MES reflects simply the system usage. It is related to the offered features and functionalities adopted and used by companies. The main MES functionalities were summarized around eleven main functions which are: Workflow planning, resource management, production unit control, information control, operation data logging, staff management, quality management, process management, maintenance management, lot traceability and performance analysis [5]. This definition was also the fundamentals of many standards such as IEC644. This standard brought a concise picture of MES main functionalities which are: Definition management, resource management, detailed scheduling, dispatching, execution management, tracking, data collection and analysis [9].

Int J Elec \& Comp Eng, Vol. 11, No. 4, August 2021 : 3347 - 3355 
The PU is the basis of the well-known technology acceptance model (TAM). This variable was originally elaborated by Davis in 1985 on the basis of many psychological studies [10]. This same model was extended and used to analyze the adoption and use of information systems (IS). In [11], several cases using the TAM model for the adoption analysis of specialized IS such as MRP or decision support systems (DSS) were demonstrated.

\subsection{MES Interoperability requirements}

MES plays a central role between the shop floor and the management level. Hence, ensuring a high level of integration with other enterprise information systems is of paramount importance. For instance, MES should be able to communicate and exchange data; on one hand; with business management applications such as enterprise resource planning (ERP) applications, which are considered mainly to improve supply chain management and have an instant access to reliable information for better management decision making [12]. On the other hand, MES needs to interact with Production and processes management related systems such as supervisory control and data acquisition (SCADA) systems or radio frequency identification (RFID) systems, responsible for the control of production execution [13] as shown in Figure 1. In [14], Veile et al. emphasized the importance of vertical and horizontal integration of MES in the context of Industry 4.0 strategy for manufacturing companies.

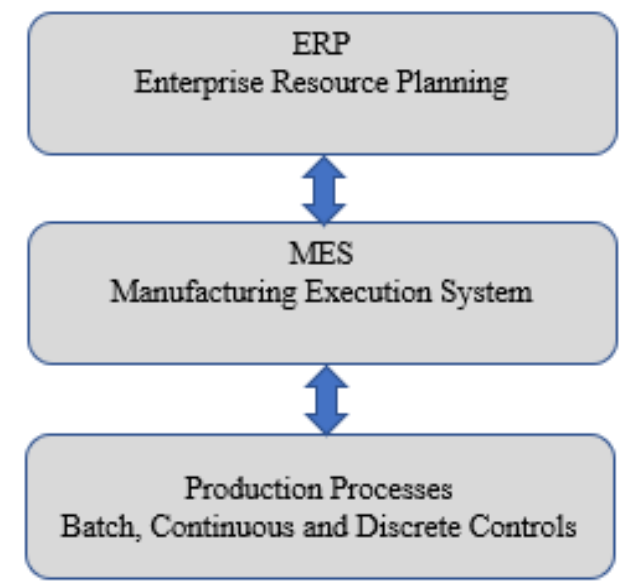

\section{Business Management Level}

Production Management level

Shop floor level

Figure 1. MES positioning within the production pyramid

Dalibor et al. [15] investigated the importance of the integration between MES and ERP for a company in the automotive industry for the purpose of ensuring real time information to the employees and efficiency in responding to changes. Xinyou and Hao [16] suggested a platform based on J2EE (Java to Enterprise Edition) in order to facilitate the information exchange between ERP and MES in real time. Meilin et al. [17] suggested a solution based on an intermediary enterprise services BUS (ESB) in order to make a smooth integration between MES and ERP and ensure a real time closed loop with MRP and other available systems as well. The ESB is an intermediary layer responsible for making smooth communication between two nodes, using service oriented architecture.

\subsection{Company profile}

Company profile refer mainly to the type of industry, the type of manufacturing process the company is dealing with and the company size. In [2], Arica and Powell indicated that industry fit is a key requirement for the success of MES adoption. In addition, the German association of engineering (ZVEI) also highlighted the differences and similarities of MES application in both process and manufacturing industries, with a list of functionalities that are common and specific for each type of industry [18]. For example, while manufacturing companies in automotive sector might choose standard MES modules such as process/ product tracking and KPIs module calculation for mainly operation efficiencies, food and pharmaceuticals companies may choose specific MES modules such as recipe procedure control (RPC) in order to comply with pure regulatory requirements. In [19], the company characteristics and size were highlighted as one of the main parameters within the organizational structure aspect for technology adoption model presented by Rogers. 


\section{RESEARCH METHOD}

The Figure 2 reports the followed method for measuring manufacturing companies' perception toward MES. The method will use the three dimensions explained in the theoretical framework. The analysis will be elaborated using PLS-SEM algorithm.

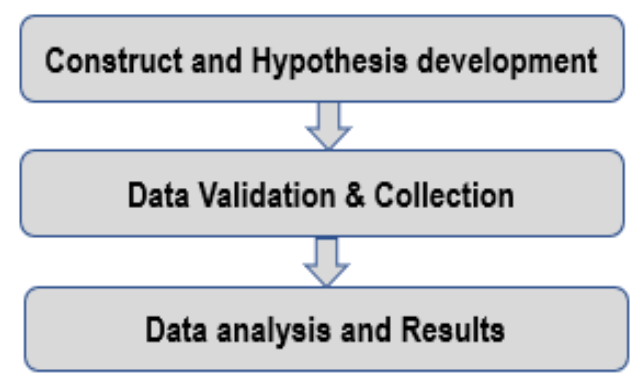

Figure 2. Method description

\subsection{Construct and hypothesis development}

Based on the conducted interviews and three identified elements in section 2 above, the two following hypotheses were identified as a foundation of our construct in Figure 3.

H1: The MES integration capabilities have a significant impact on the perceived usefulness

$\mathrm{H} 2$ : The company profile has a significant impact on perceived usefulness of MES

Each latent variable will be linked to a specific set of observed variables which were identified and validated in the next section.

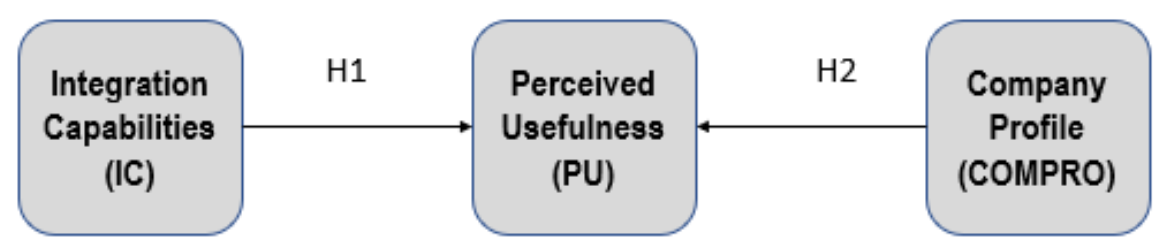

Figure 3. Structural model

\subsection{Data validation and collection}

In order to identify the observed variables that would be the basis of our measurement model, we relied on literature review and experts' judgement from the MSIs. For the PU latent variable, we will use the most important MES modules adopted by companies which are: The data acquisition module (DAM), The key performance indicators (KPI) module, the plant resources management (PRM) module, the quality management (QM) module, the production tracking (TRK) module and the production sequencing (SEQ) module. The IC latent variable will be based on the integration MES has with other software applications. We identified three main solutions which are ERPs, MRPs and SCADA systems as main solutions for MES vertical integration by companies. For the COMPRO latent variable, we will rely on the operating industry, Company type and type of manufacturing process. The Table 1 summarizes the description of each module and literature source.

The data collection phase was elaborated via a questionnaire addressed to MSIs customers using MES already. We focused on making the survey easy to understand and to fill to encourage the participation of many respondents as possible and we used "Google Form" as a survey tool. The survey focused on gathering data about the company profile, the company's assessment of each MES module and the integration aspects with existing software assets as defined earlier. The questionnaire structure summary was as follow:

- Company data:

a) Company type: The Company's number of employees will give us an insight on its type: Very small industry (VSI), small industry (SI), medium industry (MI), large industry (LI) 
b) Industry: The industry in which the company is operating

c) Process type: The type of production process (Discrete/Batch/Continuous).

- Acquired MES solution data:

a) Solution name

b) The company's evaluation of different MES features using 0-10 scale (0: Non-Applicable/1: Not very important/10: Extremely important).

- MES integration with existing software assets:

a) Software assets, if applicable, would be ERP/MRP/SCADA

b) Integration (Non-Applicable/Standard/customized)

c) Using the help of MSIs we targeted a sample of 60 manufacturing companies.

Table 1. Identified MES modules with description and source

\begin{tabular}{cccc}
\hline $\begin{array}{c}\text { Latent } \\
\text { Variable }\end{array}$ & Observed & Description & Source \\
\hline Pariable & DAM & Data gathering about process execution from other systems & {$[5,6,18]$} \\
& KPI & Calculation of identified KPI values & MSIs Expert \\
& PRM & Control of personnel and machinery & Judgement \\
& QM & Product Quality control and compliance with Procedures & \\
& TRK & Product tracking and tracing & \\
& SEQ & Location of production and the associated order & \\
\end{tabular}

\subsection{Data analysis}

For data analysis phase, we will rely on partial least squares-structural equation modelling (PLSSEM) technique. The choice of PLS-SEM was motivated by the following reasons:

- The wide application of PLS-SEM technique in information systems [20]. Actually, the authors reported an increasing use of PLS-SEM by IS researchers for exploratory research and theory developments purposes.

- PLS-SEM technique does not emphasize data normality as a precondition [21].

- The number of observations which is inferior to 100 observations [20]. According to [22], the maximum number of arrows pointing at a latent variable should be 2 considering the number of observations we have.

The PLS-SEM algorithm consists in 2 major stages [23]:

- Stage 1 encompasses four stapes that aim at calculating the latent variables score.

a) Step 1: Outer approximation of latent variables scores. In our case, there will be three scores corresponding to the IC, PU and COMPRO latent variables.

b) Step 2: Estimation of proxies for structural model between latent variables construct (IC->PU) \& (COMPRO->PU).

c) Step 3: Inner approximation of latent construct score based on scores from step 1 and step 2 .

d) Step 4: estimation of proxies for coefficients in the measurement models, that is for the path between observed variables and latent variables.

- Stage 2 deals with the final estimates of coefficients using the ordinary least squares method for every partial regression in the model.

For the assessment of our model, we will assess first the construct's reliability and validity using: cronbach 'alpha (CA), composite reliability (CR) and average variance extracted (AVE) indicators. CA and $\mathrm{CR}$ evaluate how well the observed variables would explain the latent construct. This said, $\mathrm{CR}$ is considered a better indicator of consistency than $\mathrm{CA}$ since it relies on the standardized loadings of the observed variables. Average variance extracted (AVE) is used as an indication for both convergent and divergent validity [24]. It indicates the average similarity for each latent variable.

Second, we will assess the discriminant validity using: Fornell-larcker criterion and heterotraitmonotrait (HTMT) ratio. The Fornell-Larcker criterion ensures that for any latent variable, the shared variance with its observed variables is above the variance that it has with any other latent variable. This is translated by square root of AVE being greater than the correlation with any other latent variable. The HTMT ratio is defined as the ratio between correlations of different constructs and correlations of indicators between the same construct. We will also use the variance inflation factor (VIF) for multicollinearity evaluation. That is to assess whether two or more variables are highly intercorrelated [23]. We used the latest SmartPLS software (Version 3.3.2) since it was widely adopted and used by academics for PLS-SEM related studies, for its ease of use and also the availability of support forum. 


\section{RESULTS AND DISCUSSION}

\subsection{Results presentation}

Among sixty questionnaires sent to different MES customers, we received fifty-one valid responses. This number of observations is acceptable for PLS-SEM according to [20] and considering that the MES technology is relatively new to the Moroccan market. The Table 2 provides the profile of the respondents accordingly:

Table 2. Respondents profile

\begin{tabular}{cccc}
\hline Item & & Frequency & Percentage \\
\hline Industry & Automotive & 12 & $24 \%$ \\
& Pharmaceutical & 5 & $10 \%$ \\
& Food & 10 & $20 \%$ \\
& Metallurgical & 7 & $14 \%$ \\
& Plastics & 9 & $18 \%$ \\
Process Type & Paper & 6 & $12 \%$ \\
& Glass Trans. & 2 & $4 \%$ \\
Company & Batch & 25 & $49 \%$ \\
Type & Discrete & 3 & $6 \%$ \\
& Continuous & 23 & $45 \%$ \\
& Large (>1000) & 7 & $14 \%$ \\
& Medium (500-1000) & 14 & $27 \%$ \\
& Small (100-500) & 24 & $47 \%$ \\
& Very Small (<100) & 6 & $12 \%$ \\
\hline
\end{tabular}

We calculated the factors' loadings and their significance using the resampling method (Bootstrapping). Figure 4 gives a concise view about the results for our inner and outer models along with each factor loading value and associated p-value. With regards to our inner model, the results associated with the two elaborated hypotheses are reported in Table 3. Both hypotheses are supported which confirm a positive relationship of the COMPRO and IC variables of MES with the PU. The $\mathrm{R}^{2}$ for the PU variable is equal 0.44 which suggests that $44 \%$ of the variance in PU is explained by the two identified latent variables [24]. Regarding the outer measurement model, the Table 4 summarizes the items reliability, convergent and discriminant validity.

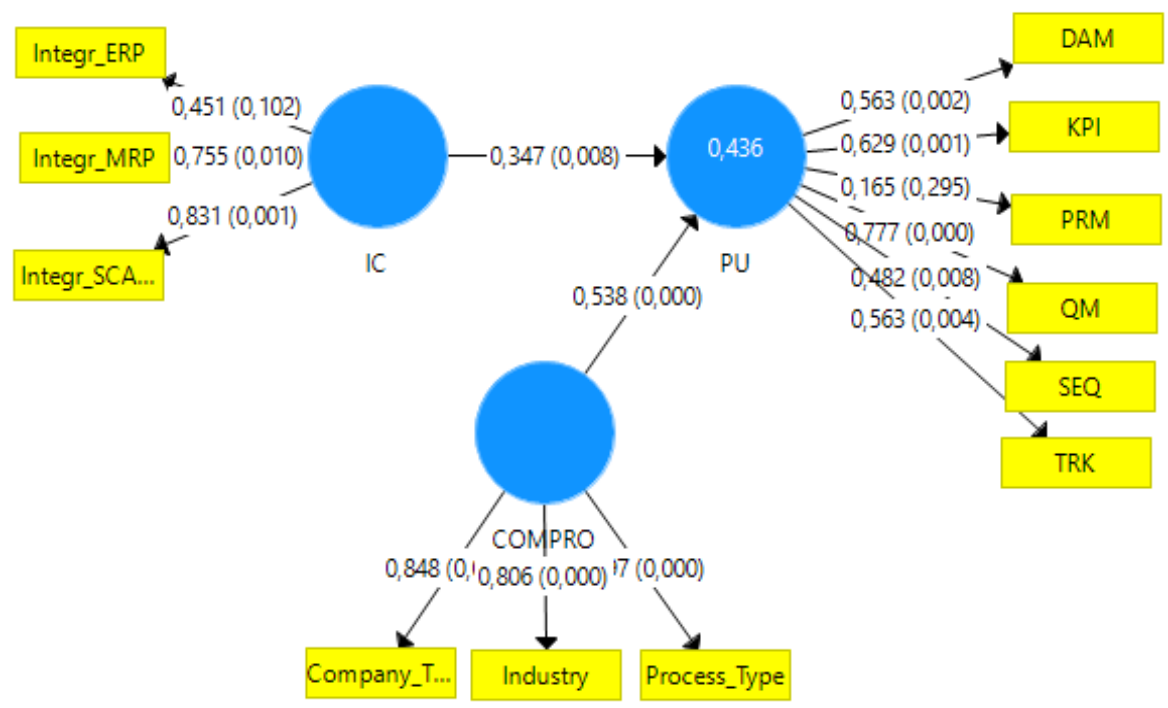

Figure 4. Results for inner and outer models

Table 3. Results associated with the inner model

\begin{tabular}{cccccc}
\hline Hypotheses & Path & Path Coefficient & T-Statistics & P-value & Confirmed (Y/N) ? \\
\hline H1 & IC- $>$ PU & 0.54 & 4.71 & 0.00 & Y \\
H2 & COMPRO->PU & 0.35 & 2.32 & 0.01 & Y \\
Notes: $\mathrm{R}^{2}=0.44$ (PU) with a T-Stat $=5.89$ and p-value $=0.00$ & & & \\
\hline
\end{tabular}


Table 4. Results associated with the measurement model

\begin{tabular}{|c|c|c|c|c|c|c|c|c|}
\hline $\begin{array}{l}\text { Construct } \\
\text { Variables }\end{array}$ & AVE & CR & $\begin{array}{c}\text { Cronbach } \\
\text { Alpha }\end{array}$ & Item & VIF & Loading & P-value & $\begin{array}{c}\text { Relevant? } \\
\text { Y/N* }\end{array}$ \\
\hline \multirow{3}{*}{ PU } & \multirow{4}{*}{0.33} & \multirow{4}{*}{0.68} & \multirow{3}{*}{0.54} & KPI & 1.17 & 0.58 & 0.00 & Y \\
\hline & & & & $\mathrm{QM}$ & 1.42 & 0.73 & 0.00 & $Y$ \\
\hline & & & & SEQ & 1.26 & 0.46 & 0.01 & $\mathrm{~N}$ \\
\hline \multirow{3}{*}{ IC } & & & \multirow{3}{*}{0.52} & TRK & 1.14 & 0.54 & 0.00 & $\mathrm{Y}$ \\
\hline & \multirow{2}{*}{0.47} & \multirow{2}{*}{0.65} & & Integr_SCADA & 1.10 & 0.74 & 0.00 & $\mathrm{Y}$ \\
\hline & & & & Company_Type & 1.57 & 0.83 & 0.00 & $Y$ \\
\hline \multirow{2}{*}{ COMPRO } & \multirow{2}{*}{0.61} & \multirow{2}{*}{0.82} & \multirow{2}{*}{0.70} & Industry & 1.26 & 0.79 & 0.00 & $Y$ \\
\hline & & & & Process_Type & 1.45 & 0.67 & 0.00 & $Y$ \\
\hline
\end{tabular}

*: The assessment of relevancy is made on the basis of a cutoff value of 0.5 for loadings [25]

The data reliability was measured using Cronbach's alpha which reported moderated to high score values: 0.52 for IC (moderate), 0.54 for PU (moderate) and 0.7 for COMPRO (high) according to Hinton [26]. For the AVE, its value should be greater than 0.5 threshold as reported by Chin (1998) and Hock \& Ringle (2006). Fornell-Larcker suggested that AVE values below 0.5 could also be acceptable with the condition that composite reliability (CR) value is higher than 0.6, which is applicable in our case [27].

Regarding the discriminant validity, assessed using both Fornell-Larcker and HTMT criteria, the Tables 5 and 6 respectively confirm that the latent constructs are definitely not related. That is HTMT is below the cutoff value of 0.9 and the values that appear in the diagonal line (Square root of AVE) are higher than values below them [24].

The last item that we check which indicate if our significance tests are reliable is the VIF indicator. This indicator should be below the cutoff value of 4.0 and we can see clearly that all VIF values are below 2.0 for our model. The multicollinearity criterion is very important since it impacts the importance of independent variables [24].

Table 5. Fornell-Larcker criterion results

\begin{tabular}{cccc}
\hline & COMPRO & IC & PU \\
\hline COMPRO & 0.79 & & \\
IC & 0.07 & 0.7 & \\
PU & 0.56 & 0.39 & 0.56 \\
\hline
\end{tabular}

Table 6. HTMT ratio values

\begin{tabular}{cc}
\hline Relation & Value \\
\hline IC->COMPRO & 0.48 \\
PU->COMPRO & 0.8 \\
PU->IC & 0.85 \\
\hline
\end{tabular}

\subsection{Results analysis}

The model developed in section 4.1 analyzed the success of MES based on the IC and COMPRO variables. The results demonstrate the positive impact of these two variables on MES system use by companies. The Delone and McLean model reported the different dimensions of IS success [28]. System quality is one of the six dimensions identified and it is related system integration and importance among other parameters. The model also confirms the impact of system quality on system use [28]. Our model not only confirms the same observation, by demonstrating the impact of MES IC on MES use but also by adding the company profile part as dimension of success.

Regarding the IC dimension, the value and success of MES comes mainly from its integration with SCADA and MRP systems respectively. Actually, MES uses all data reported from SCADA for technical analysis and decision-making regarding production schedules, planning and quality assurance. MES, on the other hand, send back data to the MRP tool about production execution status and used materials and quantities in a more detailed manner. MRP is more dedicated for production planning tasks, scheduling and inventory control and does provide macro production planning as input to MES.

Interestingly, the MES integration with ERPs was found insignificant which means a lack of commitment of Moroccan manufacturing companies to integrate both systems. In fact, the integration between the two systems might require extra integration and financial efforts and might also imply 
organizational adjustments, according to MSIs experts. Oman et al. [29] confirmed the difficulties faced by emerging countries with regards to ERP and MES integration. In addition, they demonstrated the positive impact behind this integration on several operational metrics such as on-time delivery of the product, order fulfilment cycle time and delivery and rework costs. While, Panetto and Molina (2008) highlighted in [30] that enterprise information modelling and absence of reference architecture models were key challenges for enterprise applications integration within manufacturing companies. The Business to manufacturing markup language (B2MML) helped implementing ISA95 standard which participated in improving the data exchange between the two systems [31]. The difficulty for manufacturing companies would be having applications from vendors that don't consider this standard in their development process. Experts working for the interviewed MSIs also added that usual discordances between commercial and production departments might also be considered as hurdle to this integration.

Regarding MES system usefulness, the results show that QM, KPI, DAM and TRK modules were the most important for Moroccan manufacturing companies respectively. SEQ factor loading's score didn't meet the criterion and PRM module was found insignificant. One reason that can explain these findings is that some of these functionalities are handled either manually or by other organization functions or software solutions. In fact, for the personnel resource's management functionality handled digitally by the PRM module, human resources departments are using instead the time tracking sheets manually. Dealing with the monitoring of physical assets performances and human resources involved in the production processes. For the SEQ module, responsible for inter alia tasks order sequencing, might also overlap with the scheduling capabilities of the MRP, according to MSI experts.

With regards to the second dimension, The COMPRO variable was related to three observed variables: Industry, Process type and company type which were found all significant and relevant. While literature argued that the size of the company would not be relevant, the process type and industry would be the most important elements to consider [32]. The company size, however, was used to give us a relative idea on the company's financial turnover, considering that companies wouldn't provide such financial information.

Another interesting observation is that companies didn't show any interests in advanced MES modules such as Analytics. This module relies on big data techniques and artificial intelligence algorithms in order to analyze on real time basis different production data. As emphasized by ZVEI in [9], this module is of paramount importance for embracing digital operation concept.

\section{CONCLUSION}

Our study analyzed the perception that manufacturing companies have about MES use. The study was conducted with the assistance of MSIs experts in an emerging market and targeted more than 50 manufacturing companies that acquired MES already. The companies' feedbacks were structured analyzed using PLS-SEM. We concluded that MES value is derived mainly from the adoption of production tracking, quality management, KPIs calculation and monitoring and the data acquisition modules. Furthermore, the horizontal integration is performed mainly with MRP and SCADA systems, putting integration with ERPs at the bottom of the ladder. This type of study would be a good assessment tool for MES vendors and Integrators to better evaluate and understand the manufacturing companies needs. This will allow them adapt their offerings accordingly, especially with the expected increasing interest towards MES with the implementation of digital operations strategies falling within Industry 4.0 initiative.

\section{ACKNOWLEDGEMENTS}

The authors would like to thank the General managers of the MES integration companies located in Morocco for their assistance and kind support to realize this study during the whole study period.

\section{REFERENCES}

[1] M. Ghobakhloo, "The future of manufacturing industry: a strategic roadmap toward Industry 4.0," Journal of Manu Tech Management, vol. 29, no. 6, pp. 910-936, Oct. 2018, doi: 10.1108/JMTM-02-2018-0057.

[2] E. Arica and D. J. Powell, "Status and future of manufacturing execution systems," in IEEE Int. Conf. on Industrial Engineering and Engineering Management (IEEM), 2017, pp. 2000-2004, doi: 10.1109/IEEM.2017.8290242.

[3] P. Helo, M. Suorsa, Y. Hao, and P. Anussornnitisarn, "Toward a cloud-based manufacturing execution system for distributed manufacturing," Computers in Industry, vol. 65, no. 4, pp. 646-656, May 2014.

[4] M. McClellan, "Introduction to Manufacturing Execution Systems," MES Conference and Exposition, Baltimore, Maryland, 2001.

[5] J. Fraser, "The MES performance advantage: Best of the best," Industry Directions, 2004. 
[6] M. I. Mahmoud, H. H. Ammar, Mohamed. M. Hamdy, and M. H. Eissa, "Production operation management using Manufacturing Execution Systems (MES)," in 2015 11th International Computer Engineering Conference (ICENCO), Cairo, Egypt, 2015, pp. 111-116, doi: 10.1109/ICENCO.2015.7416334.

[7] J. M. S. das Neves, G. K. Akabane, F. A. S. Marins, and R. Kanaane, "Deployment the MES (Manufacturing Execution System) aiming to improve competitive priorities of manufacturing," Ind. Jour. Man. \& Prod., vol. 6, no. 2, pp. 449-463, Jun. 2015, doi: 10.14807/ijmp.v6i2.233.

[8] R. Franzosa, "Magic Quadrant for Manufacturing Execution Systems," Gartner Research, 2019.

[9] ZVEI Association, "Industrie 4.0: MES-Prerequisite for Digital Operation and Production Management. Tasks and Future Requirements,” ZVEI Association, Automation Division, Aug. 2017.

[10] N. Marangunić and A. Granić, "Technology acceptance model: a literature review from 1986 to 2013," Univ Access Inf Soc, vol. 14, no. 1, pp. 81-95, Mar. 2015, doi: 10.1007/s10209-014-0348-1.

[11] Y. Lee, K. A. Kozar, and K. R. T. Larsen, "The Technology Acceptance Model: Past, Present, and Future," CAIS, vol. 12, 2003, doi: 10.17705/1CAIS.01250.

[12] M. Noureddine and K. Oualid, "Extraction of ERP Selection Criteria using Critical Decisions Analysis," IJACSA, vol. 9, no. 4, 2018, doi: 10.14569/IJACSA.2018.090418.

[13] H. Meyer, F. Fuchs, and K. Thiel, "Manufacturing execution systems optimal design, planning, and deployment," New York, London: McGraw-Hill, 2009.

[14] J. W. Veile, D. Kiel, J. M. Müller, and K.-I. Voigt, "Lessons learned from Industry 4.0 implementation in the German manufacturing industry," JMTM, Aug. 2019, doi: 10.1108/JMTM-08-2018-0270.

[15] B. Dalibor, S. Darko, L. Bojan, and C. Ilija, "The Implementation of ERP and MES Systems as a Support to Industrial Management Systems," International Journal of Industrial Engineering and Management (IJIEM), Serbia, vol. 9, no. 2, pp. 77-86, 2018.

[16] Y. Xinyu and L. Hao, "Study on key technologies of MES/ERP integration based on JCA," Presented at the Int. Conf. on Networking and Digital Society, vol. 2, 2010, pp. 580-584, doi: 10.1109/ICNDS.2010.5479426.

[17] W. Meilin, Z. Xiangwei, and D. Qingyun, "An Integration Methodology Based on SOA to Enable Real-Time Closed-Loop MRP between MES and ERP," in 2010 International Conference on Computing, Control and Industrial Engineering, Wuhan, China, 2010, pp. 101-105, doi: 10.1109/CCIE.2010.33.

[18] ZVEI Association, "Manufacturing Execution Systems (MES): Industry specific requirements and solutions," ZVEI Association, Automation Division, Jul. 2001.

[19] T. Oliveira and M. F. Martins, "Literature Review of Information Technology Adoption Models at Firm Level," The Electronic Journal Information Systems Evaluation, vol. 14, no. 1, pp. 110-121, 2011.

[20] J. Hair, C. L. Hollingsworth, A. B. Randolph, and A. Y. L. Chong, "An updated and expanded assessment of PLSSEM in information systems research," Industr Mngmnt \& Data Systems, vol. 117, no. 3, pp. 442-458, Apr. 2017, doi: 10.1108/IMDS-04-2016-0130.

[21] S. A. Samani, "Steps in Research Process (Partial Least Square of Structural Equation Modeling (PLS-SEM))," International Journal of Social Science and Business, vol. 1, no. 2, 2016, Art. no. 12.

[22] K. K. K. Wong, "Partial Least Squares Structural Equation Modeling (PLS-SEM) Techniques Using SmartPLS," Marketing Bulletin, vol. 24, 2013.

[23] M. Sarstedt, C. M. Ringle, and J. F. Hair, "Partial Least Squares Structural Equation Modeling," Handbook of Market Research in C. Homburg, M. Klarmann, and A. Vomberg (eds), Cham: Springer International Publishing, 2017, pp. 1-40. [Online]. Available: http://link.springer.com/10.1007/978-3-319-05542-8_15-1.

[24] G. D. Garson, "Partial Least Squares: Regression and Structural Equation Models," NC: Statistical Associates Publishing, 2016.

[25] A. H. Memon and I. A. Rahman, "SEM-PLS Analysis of Inhibiting Factors of Cost Performance for Large Construction Projects in Malaysia: Perspective of Clients and Consultants," The Scientific World Journal, vol. 2014, pp. 1-9, 2014, doi: 10.1155/2014/165158.

[26] M. Aboaoga, M. J. A. Aziz, and I. Mohamed, "Information System Success Framework based on Interpersonal Conflict Factors," International Jornal of Electrical and Computer Engineering (IJECE), vol. 8, no. 5, Oct. 2018, Art. no. 3740, doi: 10.11591/ijece.v8i5.pp3740-3746.

[27] C. C. Huang, Y. M. Wang, T. W. Wu, and P. A. Wang, "An Empirical Analysis of the Antecedents and Performance Consequences of Using the Moodle Platform," International Journal of Information and Education Technology, vol. 3, no. 2, pp. 217-221, 2013, doi: 10.7763/IJIET.2013.V3.267.

[28] W. H. Delone and M. Ephraim, "The DeLone and McLean Model of Information Systems Success: A Ten-Year Update,” J. of Management Infor. Sys., vol. 19, no. 4, pp. 9-30, Apr. 2003, doi: 10.1080/07421222.2003.11045748.

[29] S. Oman et al., "Integration of MES and ERP in supply chains: effect assessment in the case of the automotive industry," Teh. vjesn., vol. 24, no. 6, Dec. 2017, doi: 10.17559/TV-20160426094449.

[30] H. Panetto and A. Molina, "Enterprise integration and interoperability in manufacturing systems: Trends and issues," Computers in Industry, vol. 59, no. 7, pp. 641-646, Sep. 2008, doi: 10.1016/j.compind.2007.12.010.

[31] F. Wang, F. Pan, and P. Li, "The Perspective of B2MML Based on Implementation," in Proceedings of the 2017 2nd Int. Conf.on Auto., Mechanical Cont. and Computational Enginee., 2017, doi: 10.2991/amcce-17.2017.167.

[32] J. Kletti, “Manufacturing Execution Systems (MES),” Berlin, London: Springer, 2007. 